\title{
Assessment of Genetic Diversity of Sugarcane (Saccharum spp.) Genotypes through Biochemical Approach
}

\begin{abstract}
Background: Sugarcane is very important industrial and cash crop in Pakistan and in many countries of the world. It is worldwide an essential source of commercial sugar accounting for nearly 75 per cent of the world sugar production. Biochemical screening is first step in breeding to select superior genotypes in further breeding program.

Methods: The experimental investigations were carried out on 10 different genotypes of sugarcane during consecutive years i.e., 2010-2012 to determine their genetic diversity by biochemical approach and SDS-PAGE analysis. The data on biochemical parameters i.e. reducing and non-reducing sugar, protein content, vitamin $\mathrm{C}$, iron content, phosphorus content, calcium content and magnesium content in juice samples of various genotypes was recorded to assess biochemical composition.

Result: The genotypes SPF-213, LHO83-153, CP-72-2086 performed better than other ones for reducing and non-reducing sugar, protein content, vitamin C and minerals content. However, on the basis of overall biochemical constituents CP-72-2086 was most efficient genotype. Electrophoretic mobility through SDS-PAGE was revealed clear genetic diversity among genotypes. As genotype S-06-US-469 and S-06-US-312 which showed unique pattern from common ancestors. These diverse genotypes could be successfully utilized in hybridization for improvement of crop.
\end{abstract}

Key words: Protein polymorphism, Reducing and non-reducing sugar, Sugarcane.

\section{INTRODUCTION}

Sugarcane (Saccharum officinarum L.) is a perennial monocotyledonous crop, cultivated in tropical and subtropical areas of worldwide. It is grown in many areas of the world due to its nutritious juice, from which sugar is obtained. It stores high concentration of sucrose in the internodes of the stem. It is also yielded for alcohol, medicinal products, animal feed, biomanure, electricity, chemical etc (Xiao et al. 2017). Sugarcane (Saccharum officinarum L.) has broad range of fiscal significance owing to its main and by-products (Yadav et al. 2012). In our country it contributes $2.9 \%$ to the value added in the agriculture and $0.6 \%$ to GDP. It caters as a main raw material for refined sugar and gur production. However its production was estimated at 66.88 million tonnes in the year of 2020 , although its production was estimated at 67.174 million tonnes in the year of 2019 . The production obtained from year of 2020 was declined by $0.4 \%$ over the production of 2019 (Economic Survey of Pakistan, 2020). Commercial sugarcane belonging to the genus Saccharum is an essential crop accounting for nearly $75 \%$ of sugar production worldwide (Commodity Research Bureau, 2015).

Sugarcane juice is nutritious, diuretic, natural and cold in nature utilizes around the tropics and subtropics. So it can be valued as beverage because it contains sucrose, starch, phosphatides, organic acids, glucose, fructose, proteins, amino acids, vitamins and micronutrients which are essential for human growth (Nishad et al. 2017). Besides, it is considered to cure from dysuria, hemorrhage, jaundice and different urinary and cardiovascular diseases (Pradhan et al. 2019). Biochemical and physiological studies have been made from dissimilar outlooks on sugarcane (Kumar et al. 2019).
Department of Plant Breeding and Genetics, PMAS-Arid Agriculture University, Rawalpindi, Pakistan.

Corresponding Author: Mariam Khurshid, Department of Plant Breeding and Genetics, PMAS-Arid Agriculture University, Rawalpindi, Pakistan. Email: marikhan11@gmail.com

How to cite this article: Khurshid, M. (2022). Assessment of Genetic Diversity of Sugarcane (Saccharum spp.) Genotypes through Biochemical Approach. Agricultural Science Digest. 42(1): 38-42. DOI: 10.18805/ag.DF-377.

Submitted: 09-07-2021 Accepted: 21-10-2021 Online: 07-11-2021

The composition of sugarcane juice is responsive to weather changes throughout the harvest, varietal diversity is more important than seasonal variations and varieties are reliable from year to year in relative amount of starch, total polysaccharides and proanthocyanidin (Ansari et al. 2013). Singh et al. (2015) performed a comprehensive study on phytoconstituents (fatty acid, alcohol, phytosterols higher terpenoids flavonoids $\mathrm{O}$ - and $-\mathrm{C}$-glycosides phenolic acids etc.) of sugarcance juice. They also shed light on importance of phytoconstituents for manufacturing specific medicinal products and ultimately aiding in Pharmacological study. Nutritional analysis of sugarcane juice revealed that it contained total sugar (16.33\%), water (82.91), vitamin-c (3.4 $\mathrm{mg} / 100 \mathrm{ml}$ ) and reducing sugars $(0.50 \%)$ (Sankhla et al. 2012). Babiker et al. (2015) evaluated quality traits of different sugarcane genotypes as well as impact of separan on juice colors was revealed.

SDS-PAGE is a technique used to detect the protein diversity among different genotypes based on deviation in molecular size to discriminate different protein sub-units. 
Proteins difference may be as minor as one percent in their through the gel matrix electrophoretic mobility (Jiang et al. 2016). Srivastava and Gupta (2002) analyzed protein diversity in a large number of sugarcane genotypes through SDS-PAGE and concluded that this technique is speedier and more accurate than the morphological one. Mishra et al. (2011) analyzed protein polymorphism through SDS-PAGE using 50 genotypes of sugarcane collected from Indonesia and India. Results showed that $54 \%$ genotypes were highly polymorphic in nature.

Hence it is necessary to characterize different varieties biochemically for their further selection in breeding program to obtain desirable quality. The current study focused on analysis of biochemical composition and biochemical diversity among different genotypes of sugarcane. Besides, protein polymorphism among various genotypes of sugarcane was determined through SDS-PAGE.

\section{MATERIALS AND METHODS}

The investigation was accomplished at the experimental area during consecutive years i.e., 2010-2012 in the Department of Plant Breeding and Molecular Genetics (PBMG), The University of Poonch, Rawalakot, Azad Kashmir. The study was carried out to investigate the biochemical and protein diversity of ten Pakistani commercial varieties of sugarcane (Saccharum officinarum L.).

\section{Plant material and analyses}

The plant material was obtained from Ayub Agricultural Research Institute, Faisalabad (AARI) including, S-06-US469, S-03-US-633, S-06-US-832, S-95-NSG-45, S-98-SP108, SPF-213, LHO 83-153, CP-72-2086, S-06-US-312 and S-60-US-300.The data on biochemical parameters i.e. reducing and non-reducing sugar, protein content vitamin $\mathrm{C}$, iron content, phosphorus content, calcium content and magnesium content of various genotypes of sugarcane was recorded to assess biochemical composition. For the estimation of protein diversity, SDS-PAGE was conducted. However, the leaf and juice sampling was done on 7 months old crop. Reducing sugar and non-reducing sugar were determined by following Benedict method (Benedict 1909). Benedict's solution is the principle reagent in both tests i.e. reducing and non-reducing sugar. Protein content was estimated by adapting colorimetric method which is based on absorbance of coomassie brilliant blue dye under acidic condition as this dye was transformed into blue and to hold protein content which was to be assayed (Bradford 1976). Vitamin C was estimated when colorless leuco-base was formed by the reduction of 2,6-dichlorophenol indophenol dye by ascorbic acid. The dehydroascorbic acid is formed when the oxidation of ascorbic acid takes place. Oxalic acid of $4 \%$ was utilized which act as the titrating medium. At the end of titration the light pink is observed, because in acidic medium the dye shows pink color (Harris and Ray 1935). Mineral contents were conducted to analyze the amount of specific inorganic components such as iron, zinc, phosphorus, calcium, magnesium through Atomic Absorption (AA) spectrophotometer as explained the technique of the Association of Official Analytical Chemists (AOAC 1990), while Phosphorus (P) was assessed calorimetrically by Association of Official Analytical Chemists (AOAC, 1990).

Prior to determine mineral contents under Atomic Absorption (AA) spectrophotometer, the wet digestion was done to digest organic matter and reduce complex molecules to their elements. Protein diversity was estimated through SDS-PAGE by determining their electrophoretic mobility.

\section{SDS-PAGE analysis}

SDS-PAGE was performed on leaf samples according to Laemmli (1970). The protein samples were extracted through protein extraction buffer by using tris $\mathrm{HCl}$ of $.05 \mathrm{M}$, with $\mathrm{pH}$ $8,02 \%$ SDS, $5 \mathrm{M}$ urea, $1 \% \beta$-mecaptoethanol and $1 \mathrm{~g}$ Bromophenol blue (BPB). Electrophoresis procedure was carried out by polyacrylamide gel with the concentration of $11.2 \%$. The solution of electrode buffer solution was poured into the bed pool of the apparatus. After whole process finally the gel was dried then analyzed and photographed.

\section{Statistical analysis}

The data were subjected to determine statistical significance of mean values for biochemical constituents as well as dendrogram was constructed for SDS-PAGE by using statistical software Statistix 8.1.

\section{RESULTS AND DISCUSSION}

\section{Biochemical studies}

Mean values with their statistical significance of different genotypes for biochemical constituents are presented in Table 1. The mean values of reducing sugar and non-reducing sugar content in sugarcane juice samples of different genotypes was found in the range of 0.52 to $1.01 \%$ and 9.05 to $12.5 \%$ respectively. The maximum value of reducing sugar content was recorded in genotype CP-72-2086 (1.01\%) while their minimum value was found in genotype S-06-US-469 (0.52\%). Similarly the maximum value of non-reducing sugar content was estimated in genotype SPF-213 (12.5\%) while their minimum value was depicted by genotype S-95-NSG-45 (9.05\%). Xiao et al. (2017) recorded reducing and nonreducing sugar content in the range of $0.46 \%$ to $0.8 \%$ and $13 \%$ to $14.5 \%$ respectively which is coincided with current study. Reducing and non-reducing sugar are very important indicators for juice quality. The lower juice quality enriches with reducing sugar (glucose, fructose) while high quality juice contains high level of non-reducing sugar (sucrose). The level of reducing sugar is usually quite high at immature or overripe crop stage. But reducing sugar assimilated for synthesis and growth of non-reducing sugar at mature stage. However water deficit condition also promotes higher sucrose content (Xiao et al. 2017).

The mean values of protein content in sugarcane juice samples of different genotypes were found in the range of 
Assessment of Genetic Diversity of Sugarcane (Saccharum spp.) Genotypes through Biochemical Approach

Table 1: Mean values and their statistical significance for biochemical constituents.

\begin{tabular}{|c|c|c|c|c|c|c|c|c|}
\hline Genotype name & $\begin{array}{c}\text { Reducing } \\
\text { sugar } \\
\%\end{array}$ & $\begin{array}{c}\text { Non-reducing } \\
\text { sugar } \\
\%\end{array}$ & $\begin{array}{c}\text { Protein } \\
\%\end{array}$ & $\begin{array}{l}\text { Vitamin } \\
\text { C } \\
\mathrm{mg} / 100 \mathrm{ml}\end{array}$ & $\begin{array}{c}\text { Iron } \\
\mathrm{Fe} \\
\mathrm{mg} / 100 \mathrm{ml}\end{array}$ & $\begin{array}{c}\text { Phosphorous } \\
\text { P } \\
\mathrm{mg} / 100 \mathrm{ml}\end{array}$ & $\begin{array}{l}\text { Calcium } \\
\text { Ca } \\
\mathrm{mg} / 100 \mathrm{ml}\end{array}$ & $\begin{array}{c}\text { Magnesium } \\
\text { Mg } \\
\mathrm{mg} / 100 \mathrm{ml}\end{array}$ \\
\hline S-06-US-469 & $0.52 e$ & $10.01 \mathrm{e}$ & $0.68 \mathrm{i}$ & $1.50 \mathrm{~cd}$ & $43.30 \mathrm{e}$ & $14.34 j$ & $85.23 i$ & $4.51 \mathrm{f}$ \\
\hline S-03-US-633 & $0.65 \mathrm{de}$ & $11.8 b c$ & $1.69 \mathrm{e}$ & $1.80 \mathrm{~b}$ & $42.32 f$ & $19.21 \mathrm{~g}$ & $89.17 \mathrm{~g}$ & $5.14 \mathrm{e}$ \\
\hline S-06-US-832 & $0.96 a b$ & $11.70 \mathrm{c}$ & $2.7 a$ & $1.60 \mathrm{c}$ & $36.5 \mathrm{i}$ & $38.35 b$ & $87.21 \mathrm{~h}$ & $4.33 \mathrm{~g}$ \\
\hline S-95-NSG-45 & $0.99 a b$ & $9.05 \mathrm{~g}$ & $0.92 \mathrm{~h}$ & $1.20 \mathrm{e}$ & $41.6 \mathrm{~g}$ & $28.67 \mathrm{e}$ & $95.67 \mathrm{e}$ & $4.24 \mathrm{~g}$ \\
\hline S-98-SP-108 & $1.00 \mathrm{a}$ & $10.05 \mathrm{e}$ & $1.44 \mathrm{~g}$ & $1.45 d$ & $39.23 \mathrm{~h}$ & $18.25 \mathrm{~h}$ & $94.23 f$ & $6.23 d$ \\
\hline SPF-213 & $0.73 \mathrm{~cd}$ & $12.50 a$ & $2.53 b$ & $1.95 a$ & $51.42 \mathrm{c}$ & $31.22 d$ & $115.19 a$ & $8.34 a$ \\
\hline LHO83-153 & $0.9 a b c$ & $11.02 d$ & $2.29 c$ & $1.60 \mathrm{c}$ & $53.34 b$ & $37.25 \mathrm{c}$ & $107.27 \mathrm{c}$ & $6.71 \mathrm{c}$ \\
\hline CP-72-2086 & $1.01 \mathrm{a}$ & $12.00 \mathrm{~b}$ & $2.14 d$ & $2.01 a$ & $60.45 a$ & $39.24 a$ & $110.56 b$ & $7.63 b$ \\
\hline S-06-US-312 & $0.8 \mathrm{bcd}$ & $11.00 \mathrm{~d}$ & $2.36 c$ & $1.75 b$ & $42.43 f$ & $15.52 \mathrm{i}$ & $87.19 \mathrm{~h}$ & $4.27 \mathrm{~g}$ \\
\hline S-60-US-300 & $0.73 \mathrm{~cd}$ & $9.70 f$ & $1.57 f$ & $1.80 \mathrm{~b}$ & $45.55 d$ & $22.33 f$ & $98.63 d$ & $5.12 \mathrm{e}$ \\
\hline
\end{tabular}

$0.68 \%$ to $2.72 \%$. The maximum value was found in S-06US-832 $(2.72 \%)$ and its minimum value was observed in S06-US-469 (0.68\%). Shi et al. (2021) found it in juice sample $(0.03 \%)$ lower than it found in its retentate sample $(0.53 \%)$ of Brazilian genotypes. The values reported by current study are far higher than those were depicted by previous study. These deviations might be due to varietal difference, agroclimatic conditions and method of crushing and preserving juice. Protein is the most essential nutrient required by humans to maintain growth, metabolism as well as body immune system. The genotypes i.e., S-06-US-832, LHO83153, CP-72-2086, S-06-US-312, SPF-213 contained abundant proteins $(>2 \%)$; hence these are beneficial and healthy for human consumption.

Vitamin $\mathrm{C}$ (ascorbic acid) content was recorded in the varying range of 1.2 to $2.0 \mathrm{mg} / 100 \mathrm{ml}$. The maximum value was found in genotype CP-72-2086 $(2.0 \mathrm{mg} / 100 \mathrm{ml})$ and its minimum value was observed in genotype S-95-NSG-45 $(1.2 \mathrm{mg} / 100 \mathrm{ml})$. Zia et al. (2019) reported its range 0.3 to $0.6 \mathrm{mg} / 100 \mathrm{ml}$, which was lower than that reported by current study. Higher vitamin $\mathrm{C}$ content surges shelf life of sugarcane juice as it prevents its deterioration for longer time. It plays an important role in hindrance PPO activity, microbial count, viscosity, titratable acidity as well as delays boosting of reducing sugars (Pradhan et al. 2019). S-60-US-300, S-06US-312 and SPF-213 and CP-72-2086 contained higher amount of ascorbic acid indicating their suitability for juice preparation. The former two and later two were statistically different from each other. These genotypes can be utilized as parents in breeding program for increasing ascorbic acid. The mean values of iron $(\mathrm{Fe})$ and phosphorous $(\mathrm{P})$ contents in sugarcane juice samples of different genotypes were found in the range of 36.50 to 60.45 and 14.34 to $39.24 \mathrm{mg} /$ $100 \mathrm{ml}$ respectively. The highest $\mathrm{Fe}$ and $\mathrm{P}$ contents were recorded in genotype CP-72-2086 $(60.45 \mathrm{mg} / 100 \mathrm{ml}$ and $39.24 \mathrm{mg} / 100 \mathrm{ml}$ respectively), while their lowest values were observed in genotypes S-06-US-832 $(36.25 \mathrm{mg} / 100 \mathrm{ml})$ and S-06-US-469 (14.34 mg/100 ml) respectively. de Souza et al. (2015) reported the Fe content $(2.4$ to $43 \mathrm{mg} / \mathrm{ml}$ ) and $\mathrm{P}(1.53$ to $4.21 \mathrm{mg} / 100 \mathrm{ml}$ ) in juice extracts of Brazilian sugarcane varieties, which were far lower than those were observed in the current study. However, calcium (Ca) and magnesium $(\mathrm{Mg})$ contents were observed in the varying range of 85.23 $115.19 \mathrm{mg} / 100 \mathrm{ml}$ and 4.24-8.34 mg/100 ml respectively. Highest mean values of $\mathrm{Ca}$ and $\mathrm{Mg}$ were found in genotype SPF-213 $(115.19 \mathrm{mg} / 100 \mathrm{ml}$ and $8.34 \mathrm{mg} / 100 \mathrm{ml}$ respectively) while their lowest mean values were observed in genotypes S-06-US-469 (85.23 mg/100 g) and S-95-NSG$45(4.24 \mathrm{mg} / 100 \mathrm{~g})$ respectively. de Souza et al. 2015 recorded mean values of $\mathrm{Ca}$ and $\mathrm{Mg}$ in sugarcane juice varied in the range of 9.00 to $10.8 \mathrm{mg} / 100 \mathrm{ml}$ and 11.7 to $13.97 \mathrm{mg} / 100 \mathrm{ml}$ respectively. The values of $\mathrm{Ca}$ are higher while values of $\mathrm{Mg}$ are lower than those reported stated by de Souza et al. (2015). These variations might be occurred due to varietal difference, agro-climatic condition difference of cultivation practices and deviated methods of grinding and preserving juice extracts. Minerals are health promoting nutrients which participate in human growth and metabolism. They also contribute to proper kidney functions and reduction of cancer cells, maintenance of blood sugar level as well as prevention of tooth decay (Singh et al. 2014). Hence the genotypes with high mineral content can be exploited in breeding program for boosting mineral level and utilize them on commercial scale.

\section{Sodium dodecyl sulphate polyacrylamide gel electrophoresis (SDS-PAGE)}

Sugarcane SDS-PAGE has been used because of its consistency and ease for protein assessment and description of genetic structure of the germplasm. Although disassembling and unfolding of protein complexes due to blue native PAGE reported by Klodmann et al. (2011). Protein profile of dissimilar genotypes is estimated and their distinct banding pattern on running gel has been noted after staining and destainig (Fig 1).

The banding pattern drawn from the photograph of gel (Fig 1) clearly indicated similarity and variation among genotypes on molecular level (Table 2). Same banding pattern was observed in first five genotypes while SPF-213, LHO 83-153 and S-60-US-300 had same banding pattern. Seven bands were found in all genotypes except CP-722086, S-06-US-312 which possessed eight bands. 
Assessment of Genetic Diversity of Sugarcane (Saccharum spp.) Genotypes through Biochemical Approach

Dendrogram (Fig 2) showed three main clusters, as cluster I contains only one genotype S-06-US-469. Custer II is divided into further clusters II (a) and II (b). Cluster II (a) include genotypes S-03-US-633, G8. Cluster II (b) included only SPF-213. Cluster III included only S-06-US-312. At linkage distance 2.2 three clusters are formed. In cluster I genotype S-06-US-469 was present showed unique pattern and variation from other genotypes. Whereas in Cluster II (a) S03-US-633, CP-72-2086 were genetically same in nature and in unique cluster reflecting similarity index in phylogenetic relationship among them belonging to same ancestors. In sub cluster II (b) the ecotypes SPF-213 was outlier in this group and showed variation from other genotypes. In main Cluster III included only S-06-US-312

Table 2: Diagrametic sketch showing SDS-PAGE results of ten genotypes of sugarcane.

\begin{tabular}{|c|c|c|c|c|c|c|c|c|c|c|}
\hline Genotype & 1 & 2 & 3 & 4 & 5 & 6 & 7 & 8 & 9 & 10 \\
\hline G1=S-06-US-469 & 0 & 1 & 1 & 1 & 1 & 1 & 1 & 1 & 0 & 0 \\
\hline G2=S-03-US-633 & 0 & 1 & 1 & 1 & 1 & 1 & 1 & 1 & 0 & 0 \\
\hline S-06-US-832 & 0 & 1 & 1 & 1 & 1 & 1 & 1 & 1 & 0 & 0 \\
\hline S-95-NSG-45 & 0 & 1 & 1 & 1 & 1 & 1 & 1 & 1 & 0 & 0 \\
\hline S-98-SP-108 & 0 & 1 & 1 & 1 & 1 & 1 & 1 & 1 & 0 & 0 \\
\hline SPF-213 & 0 & 0 & 1 & 1 & 1 & 1 & 1 & 0 & 1 & 1 \\
\hline LHO 83-153 & 0 & 0 & 1 & 1 & 1 & 1 & 1 & 0 & 1 & 1 \\
\hline CP-72-2086 & 0 & 1 & 1 & 1 & 1 & 1 & 1 & 0 & 1 & 1 \\
\hline S-06-US-312 & 0 & 1 & 1 & 1 & 1 & 1 & 1 & 0 & 1 & 1 \\
\hline S-60-US-300 & 0 & 0 & 1 & 1 & 1 & 1 & 1 & 0 & 1 & 1 \\
\hline
\end{tabular}

$1=$ Presence of protein band, $0=$ Absence of protein band.

x_1= S-06-US-469, x_2= S-03-US-633, x_3= S-06-US-832, x_4= S-95-NSG-45, x_5= S-98-SP-108, x_6= SPF-213, x_7= LHO 83-153, x_8 $=$ CP-72-2086, x_9= S-06-U S-312, x_10=S-60-US-300, M= Protein marker.

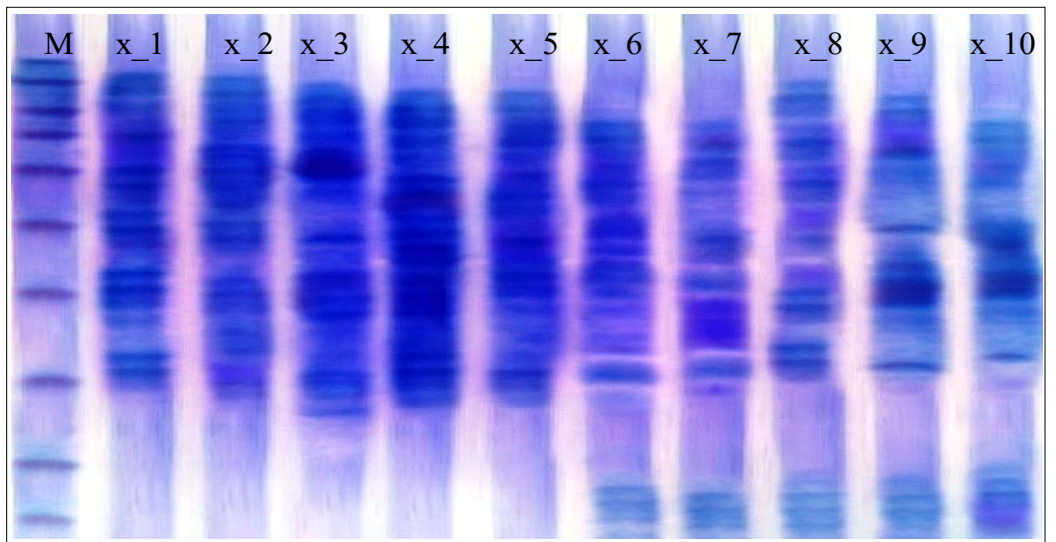

Fig 1: The photograph of SDS-PAGE gel explaining protein diversity.

Whereas, $x \_1=$ S-06-US-469, x_2= S-03-US-633, x_3= S-06-US-832, x_4= S-95-NSG-45, x_5= S-98-SP-108, x_6= SPF-213, x_7 = LHO 83-153, x_8= CP-72-2086, x_9= S-06-US-312, x_10= S-60-US-300, M= Protein marker.

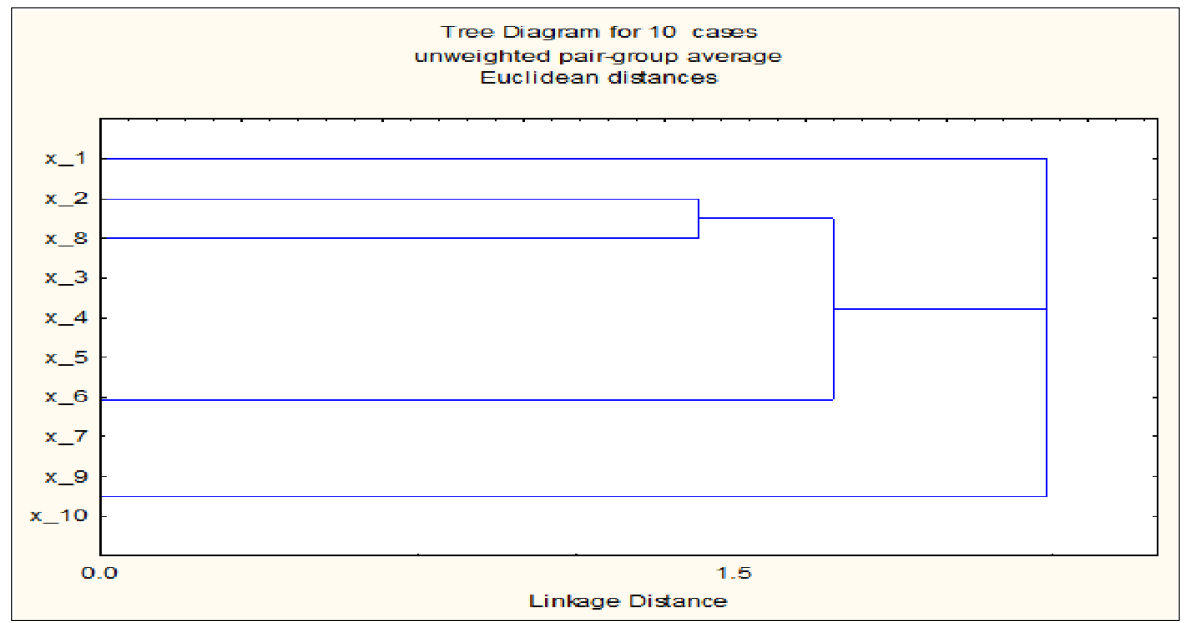

Fig 2: Dendrogram based on average linkage distance on the basis of SDS- PAGE. 
was present in unique pattern and became an outlier. They conveyed common genetic expression for SDS-PAGE while they had visibly different behavior in other biochemical parameters. In cluster II, S-03-US-633 and CP-72-2086 were grouped in same cluster and similar behavior. However remaining genotypes S-95-NSG-45, S-98-SP-108, LHO 83153 and S-60-US-300 were not being grouped in any cluster due to dissimilarity. Similar findings for sugarcane accessions were reported by Mehdi et al. (2020) who observed protein diversity in different genotypes showed bands with the range of $15-150 \mathrm{kDa}$, whereas the bands i.e., $60 \mathrm{kDa}, 70 \mathrm{kDa}$ and $90 \mathrm{kDa}$ were more common in genotypes.

\section{CONCLUSION}

The genotypes showed different pattern of variations in biochemical constituents for juice analysis. However biochemical characterization of sugarcane genotypes is the base for further evaluation but for advanced research more authentic and reliable picture of crop on molecular basis should be launched. However the genetic factors are the main reasons for triggering the biochemical diversity in sugarcane and biochemical analysis is the major part of the present study. In present study from biochemical analysis it is concluded that CP-72-2086 and SPF-213 are biochemically most efficient and genetic diverse genotypes. Besides, the polymorphism of total proteins among different genotypes of sugarcane is observed through SDS-PAGE which showed different protein bands to confirm protein diversity in sugarcane which can be helpful to produce more diverse generation. These results obtained from our investigation performed, provide new insight for future research. Sugarcane has stunning potential to accomplish the objectives of economical, nutritional importance.

\section{REFERENCES}

Ansari, M.I., Yadav, A. and Lal, R. (2013). An-overview on invertase in sugarcane. Bioinformation. 9: 464.

AOAC. (1990). Official Methods of Analysis, Association of Official Analytical Chemists, Washington, D.C., USA. Edition $15^{\text {th }}$, pp. 807-928.

Babiker, E.E. (2015). Evaluation of sugarcane juice quality as influenced by cane treatment and separn concentrations. Ph.D dissertation, University of Khartoum, Sudan, Khartoum.

Benedict, S.R. (1909). A reagent for the detection of reducing sugars. Journal of Biological Chemistry. 5: 485-487.

Bradford, M.M. (1976). Rapid and sensitive method for the quantitation of microgram quantities of protein utilizing the principle of protein-dye binding. Analytical Biochemistry. 72: 248-254.

Commodity Research Bureau (2015). CRB Commodity Yearbook. Chicago, IL: Commodity Research Bureau.

de Souza, R. B., de Menezes, J.A.S., de Souza, R.D.F.R., Dutra, E.D. and de Morais Jr, M.A. (2015). Mineral composition of the sugarcane juice and its influence on the ethanol fermentation. Applied Biochemistry and Biotechnology. 175: 209-222.

Government of Pakistan. (2019-2020). Pakistan Economic Survey Economic Advisor Wing, Finance Division. Available: http:// www.finance.gov.pk/.
Harris, L.J. and Ray, S.N. (1935). Calorimetric method for detection of ascorbic acid. Lancet. 1: 462.

Jiang, S., Liu, S., Zhao, C. and Wu, C. (2016). Developing protocols of Tricine-SDS-PAGE for separation of polypeptides in the mass range 1-30 $\mathrm{kDa}$ with minigel electrophoresis system. International Journal of Electrochemical Science. 11: 640-649.

Klodmann, J., Lewejohann, D. and Braun, H.P. (2011). Low SDS blue native PAGE. Proteomics. 11: 1834-1839.

Kumar, D., Malik, N. and Sengar, R.S. (2021). Physio-biochemical insights into sugarcane genotypes under water stress. Biological Rhythm Research. 52: 92-115.

Laemmli, U.K. (1970). Cleavage of structural proteins during the assembly of the head of bacteriophage T4. Nature. 227: 680 .

Mehdi, F., Kazim, A., Nesheman, H., Hussain, I., Azhar, A. and Galani, S. (2020). Comparative biochemical analysis of high and low sucrose accumulating sugarcane varieties at formative stage under heat stress. Journal of Agricultural Sciences. 26: 78-86.

Mishra, N., Singh, R., Singh, S., Singh, R. and Sharma, M. (2011). Evolution of genetic diversity in sugarcane (Saccharum spp.) germplasm using protein profiling. Conference: Balancing Sugar and Energy Production in Developing Countries: Sustainable Technologies and Marketing Strategies. India.

Nishad, J., Selvan, C.J., Mir, S.A. and Bosco, S.J.D. (2017). Effect of spray drying on physical properties of sugarcane juice powder (Saccharum officinarum L.). Journal of Food Science and Technology. 54: 687-697.

Pradhan, N., Kumar, D., Singh, P. and Patel, S. (2019). Status of sugarcane juice preservation processes and technologies: A review. International Journal of Chemical Studies. 7: 2720-2728.

Sankhla, S., Chaturvedi, A., Kuna, A. and Dhanlakshmi, K. (2012). Preservation of sugarcane juice using hurdle technology. Sugar Tech. 14: 26-39.

Shi, C., Xie, C., Zhang, Z., Rackemann, D., Wei, B., Hang, F. and Doherty, W.O. (2021). Sugar and value-added products derived from retentate concentrate of sugarcane juice. Journal of Cleaner Production. 278: 123915.

Singh, A., Lal, U.R., Mukhtar, H.M., Singh, P.S., Shah, G. and Dhawan, R.K. (2015). Phytochemical profile of sugarcane and its potential health aspects. Pharmacognosy Reviews. 9: 45.

Singh, S., Gaikwad, K. and Omre, P.K. (2014). Spoilage of sugarcane juice a problem in sugarcane industry. International Journal of Agricultural Engineering. 7: 259-263.

Srivastava, S. and Gupta, P. (2002). SDS and Native PAGE protein profile for identification and characterization of elite sugarcane genotypes. Sugar Tech. 4: 143-147.

Xiao, Z., Liao, X. and Guo, S. (2017). Analysis of sugarcane juice quality indexes. Journal of Food Quality, 2017: Article ID 1746982.

Yadav, S.W., Ahmad, A.Q., Rastogi, J.Y. and Lal, M.A. (2012). Tissue culture strategies in sugarcane (Saccharum officinarum L.). International Journal of Pharma and Bio Sciences. 3: 27-441.

Zia, S., Khan, M.R., Zeng, X.A., Shabbir, M.A. and Aadil, R.M. (2019). Combined effect of microwave and ultrasonication treatments on the quality and stability of sugarcane juice during cold storage. International Journal of Food Science and Technology. 54: 2563-2569. 